\title{
The Role of Polymorphisms Near IFNL3 Gene as Predictors of Residual HCV RNA in Buffy Coat after Successful Antiviral Therapy
}

\author{
Seyyed Mohammad Miri, ${ }^{1,2}$ Heidar Sharafi, ${ }^{2,3}$ Ali Pouryasin,, ${ }^{4,5}$ Bita Behnava, ${ }^{2,3}$ Maryam Keshvari, ${ }^{6}$ \\ Shima Salimi, ${ }^{3}$ Pegah Karimi Elizee, ${ }^{1}$ and Seyed Moayed Alavian ${ }^{2,3,{ }^{*}}$ \\ ${ }^{1}$ Kowsar Medical Institute, Heerlen, The Netherlands \\ ${ }^{2}$ Baqiyatallah Research Center for Gastroenterology and Liver Diseases, Baqiyatallah University of Medical Sciences, Tehran, IR Iran \\ ${ }^{3}$ Middle East Liver Diseases (MELD) Center, Tehran, IR Iran \\ ${ }^{4}$ Armin Pathobiology Laboratory, Tehran, IR Iran \\ ${ }^{5}$ Department of Biology, Arsanjan Branch, Islamic Azad University, Arsanjan, IR Iran \\ ${ }^{6}$ Blood Transfusion Research Center, High Institute for Research and Education in Transfusion Medicine, Tehran, IR Iran \\ "Corresponding author: Seyed Moayed Alavian, MD, Baqiyatallah Research Center for Gastroenterology and Liver Diseases, Baqiyatallah University of Medical Sciences, \\ Mollasadra St., Vanak, Tehran, IR Iran. Tel: +98-2188945186, Fax: +98-2188945188, E-mail: Alavian@thc.ir
}

Received 2017 February 11; Accepted 2017 February 12.

\begin{abstract}
Background and Aims: The presence of the hepatitis C virus (HCV) in cells of extrahepatic organs like peripheral blood mononuclear cells (PBMCs) have important implications for transmission, disease progression, and effective treatment of HCV-infected patients. The impact of host genetics such as polymorphisms near Interferon lambda 3 (IFNL3) on clearance of HCV RNA from buffy coat (BC) following successful clearance of HCV from plasma using Pegylated-IFN (PegIFN) and Ribavirin (RBV) treatment was evaluated in our study.

Methods: For detection of residual HCV RNA in BC samples, blood samples of 69 patients with sustained virologic response (SVR) after treatment with PegIFN and RBV were evaluated. Polymorphisms near IFNL3 gene including rs12979860 and rs8099917 were assessed using PCR-RFLP method.

Results: The most prevalent rs12979860 and rs8099917 genotypes were CT (49.3\%) and TT (62.3\%), respectively. Nine (13.04\%, 95\%CI: 7.01\% - 22.96\%) patients had HCV RNA in their BC samples. The favorable genotypes of the 2 polymorphisms (rs12979860 CC and rs8099917 TT) were more frequently observed in patients with undetectable HCV RNA in their BC samples than those with HCV RNA in their BC samples (rs12979860 CC, $45 \%$ vs. $22.2 \%, \mathrm{P}=0.016$ and $\mathrm{rs} 8099917 \mathrm{TT}, 66.7 \%$ vs. $33.3 \%, \mathrm{P}=0.01$ ).

Conclusions: The polymorphisms of IFNL3 could play a crucial role not only in spontaneous clearance of HCV and SVR rate after PegIFN and RBV therapy, but also in the clearance of HCV from BC after PegIFN and RBV therapy.
\end{abstract}

Keywords: Polymorphisms, IFNL3, HCV, PBMC, rs12979860, rs8099917

\section{Introduction}

Hepatitis $\mathrm{C}$ virus (HCV) is a single-stranded hepatotropic RNA virus, which causes chronic hepatitis in more than $70 \%$ of infected individuals (1). It has been estimated that $2.2 \%$ of the world population are suffering from chronic HCV infection. The incidence rate of $\mathrm{HCV}$ infection can be found as the highest in the eastern mediterranean region (EMRO) and Africa $(2,3)$. Seroprevalence of HCV in Iran varies from $0.2 \%$ to $1.5 \%$ and $\mathrm{HCV}$ is the most important reason for chronic liver disease in hemophilia, thalassemia, patients with renal failure, and those on hemodialysis (4). The patients with chronic hepatitis $\mathrm{C}$ infection should be treated with antiviral agents to prevent the progression of liver diseases (5). The available treatment regimens contain immunomodulatory agents such as interferon (IFN) and Pegylated-IFN (PegIFN) and/or direct-acting antiviral agents (DAAs) such as NS3 protease inhibitors, NS5A inhibitors, and NS5B polymerase inhibitors (6). The antiviral therapy could clear HCV from patient's plasma while it is not obvious whether it can result in eradication of the virus from the patient's liver and/or other extrahepatic reservoirs (7-9).

The natural history and outcome of HCV infection can be determined by various parameters of virus and host (10). The same is true for traditional treatment with IFNbased regimens $(11,12)$. Among HCV parameters, HCV genotype, HCV RNA level, and variations in HCV genome are able to change response to PegIFN and ribavirin (RBV) combination therapy $(13,14)$. Host factors such as gender, age, ethnicity, and genetic polymorphisms have remarkable effects on the outcome of HCV infection as well $(11,13$, $15,16)$. Since 2009 , many studies showed the important role of polymorphisms near Interferon lambda 3 (IFNL3) in spontaneous and IFN-based treatment-induced clearance of HCV infection $(14,17,18)$. Many studies investigated the 
impact of host genetics on clearance of HCV RNA from plasma but no study investigated the impact of host genetic parameters such as polymorphisms near IFNL3 on the clearance of HCV RNA from peripheral blood mononuclear cells (PBMCs) or buffy coat (BC) following successful clearance of $\mathrm{HCV}$ from plasma using treatments.

\section{Objectives}

This study aimed to investigate the prevalence of residual HCV RNA in BC samples following successful clearance of HCV RNA from plasma in patients treated with PegIFN and RBV. Moreover, the impact of polymorphisms near IFNL3 on the clearance of HCV from BC was evaluated.

\section{Methods}

\subsection{Study Population}

Retrospectively, 69 patients with cleared HCV infection from plasma following treatment with PegIFN and RBV (within 2012 to 2013) were studied cross-sectionally. Censusly and from all patients referred to the referral center of Tehran hepatitis clinic, we assumed the below inclusion criteria: 1) patients with chronic HCV infection (detectable HCVAb and HCV RNA for more than 6 months) prior hepatitis $C$ treatment, 2) chronic hepatitis $C$ patients who were treated with PegIFN and RBV, and 3) patients with sustained virologic response (SVR). The exclusion criteria were as follows: 1) HCV/HIV coinfection, 2) HCV/HBV coinfection, 3) HCC, and 4) liver transplantation.

Patients were treated with PegIFN- $\alpha 2$ a or $-\alpha 2 b$ and RBV for 6 to 18 months based on the HCV genotype and ontreatment response. The study population was selected consecutively from patients treated at the Tehran hepatitis clinic (Tehran, Iran) considering the above-mentioned inclusion and exclusion criteria. Undetectable HCV RNA, 6 months after treatment cessation was considered as SVR, which indicated treatment success. The ethics committee of the Baqiyatallah research center for gastroenterology and liver diseases approved the study design and ethical approaches. All study participants provided informed consent explaining the aims of our study. The authors assert that all procedures contributing to this work comply with the ethical standards of the relevant national and institutional committees on human experimentation and with the Helsinki declaration of 1975, as revised in 2008.

\subsection{Laboratory Assessments}

For detection of residual HCV RNA in BC samples, blood sample with ethylenediaminetetraacetic acid anticoagulant was collected from patients, 6 - 36 month after achiev- ing SVR. The BC was separated after 10 minutes of centrifugation at 3000 RPM. Total nucleic acid was extracted from BC using QIAamp ${ }^{\circledR}$ DNA Blood Mini Kit (Qiagen, Hilden, Germany) according to the manufacturer's instruction. The extracted nucleic acid was subjected to cDNA synthesis using RevertAid First Strand cDNA Synthesis Kit(Fermentas of Thermo Fisher Scientific, Waltham, MA, United States). Hepatitis C virus 5'-untranslated region (5'-UTR) was detected in the product of cDNA synthesis using QIAGEN $^{\circledR}$ OneStep RT-PCR Kit (Qiagen, Hilden, Germany) and the following primer set: 3'-AGCGTCTAGCCATGGCGT-5' and 3'CAAGCACCCTATCAGGCAGT-5'. The amplification of HCV 5'UTR resulted in a 234 base pair (bp) DNA fragment, which was detected on a $3 \%$ agarose gel.

In this study, rs12979860 and rs8099917 polymorphisms were assessed as the most common polymorphisms near IFNL3 gene. The detailed protocol of the polymerase chain reaction-restriction fragment length polymorphism (PCR-RFLP) method for genotyping of rs12979860 and rs8099917 polymorphisms was previously described (19).

\subsection{Statistical Analysis}

Categorical variables were expressed as frequencies and percentages, and continuous variables were expressed as the median (interquartile range). The Fisher's exact test was used to analyze the categorical variables and the Mann-Whitney U test was utilized to analyze continuous variables. The Hardy-Weinberg Equilibrium (HWE) was assessed for the rs12979860 and rs8099917 SNPs, and the linkage disequilibrium (LD) between these SNPs was calculated. $\mathrm{P}$ values less than $0.05(\mathrm{P}<0.05)$ were statistically significant. Statistical analyses were performed using SPSS version 20.0 (IBM SPSS, Chicago, IL, USA).

\section{Results}

Patients' baseline characteristics and on-treatment response were included in Table 1. Most of the studied patients were male and young with a median age of 24. Most of the patients had HCV genotype 1 infection prior to antiviral therapy. The most prevalent rs12979860 and rs8099917 genotypes were CT (49.3\%) and TT (62.3\%), respectively (Table 1). The distributions of both rs12979860 and rs8099917 genotypes were in $\operatorname{HWE}(\mathrm{P}=0.37$ and $\mathrm{P}=0.21$, respectively $)$ and the 2 SNPs were in moderate $\operatorname{LD}\left(D^{\prime}=1.0, r^{2}=0.49\right)$. During treatment, $95.6 \%$ of patients achieved complete early virologic response (cEVR).

Among study population, 9 (13.04\%, 95\%CI: 7.01\% 22.96\%) patients had HCV RNA in their BC samples. To assess the factors that determined the persistence of HCV 
Table 1. Baseline Characteristics and on-Treatment Response of the Study Population in Relation to Detection of HCV RNA in Buffy Coat

\begin{tabular}{|c|c|c|c|c|}
\hline & \multirow[t]{2}{*}{$\operatorname{All}(\mathbf{n}=69)$} & \multicolumn{2}{|c|}{ HCV RNA in BC } & \multirow[t]{2}{*}{ P Value } \\
\hline & & Not detected $(\mathbf{n}=60)$ & $\operatorname{Detected}(\mathbf{n}=\mathbf{9})$ & \\
\hline $\operatorname{Sex}^{\mathrm{a}}$ & & & & $0.582^{\mathrm{b}}$ \\
\hline Male & $62(89.9)$ & $53(88.3)$ & $9(100.0)$ & \\
\hline Female & $7(10.1)$ & $7(11.7)$ & 0 & \\
\hline Age, $y,{ }^{c}$ & $24.0(12.0)$ & $24.0(11.5)$ & $24.0(8.0)$ & $0.532^{d}$ \\
\hline Serum ALT, ${ }^{\mathbf{e}} \mathbf{I U} / \mathbf{L}^{\mathrm{c}}$ & $42.5(42.0)$ & $42.0(45.0)$ & $46.0(12.0)$ & $0.871^{\mathrm{d}}$ \\
\hline Serum AST, ${ }^{e}$ IU/L $\mathbf{L}^{\mathbf{c}}$ & $31.0(20.0)$ & $32.0(19.0)$ & $31.0(18.0)$ & $0.885^{d}$ \\
\hline HCV RNA, Log IU/mL ${ }^{c}$ & $5.9(0.7)$ & $5.9(0.7)$ & $5.8(0.7)$ & $0.428^{d}$ \\
\hline HCV genotype $^{\mathrm{a}}$ & & & & $0.452^{\mathrm{b}}$ \\
\hline 1 & $47(68.1)$ & $42(70.0)$ & $5(55.6)$ & \\
\hline $2 / 3$ & $22(31.9)$ & $18(30.0)$ & $4(44.4)$ & \\
\hline $\mathbf{r s 1 2 9 7 9 8 6 0 ^ { a }}$ & & & & $0.016^{\mathrm{f}}$ \\
\hline $\mathrm{CC}$ & $29(42.0)$ & $27(45.0)$ & $2(22.2)$ & \\
\hline $\mathrm{CT}$ & $34(49.3)$ & $30(50.0)$ & $4(44.4)$ & \\
\hline TT & $6(8.7)$ & $3(5.0)$ & $3(33.3)$ & \\
\hline $\mathbf{r s 8 0 9 9 9 1 7}^{\mathrm{a}}$ & & & & $0.010^{\mathrm{f}}$ \\
\hline $\mathrm{TT}$ & $43(62.3)$ & $40(66.7)$ & $3(33.3)$ & \\
\hline GT & $25(36.2)$ & $20(33.3)$ & $5(55.6)$ & \\
\hline GG & $1(1.4)$ & $0(0)$ & $1(11.1)$ & \\
\hline History of antiviral therapy ${ }^{a}$ & & & & $0.891^{\mathrm{f}}$ \\
\hline Naive & $56(82.1)$ & $49(81.7)$ & $7(77.8)$ & \\
\hline Relapse & $8(11.6)$ & $7(11.7)$ & $1(11.1)$ & \\
\hline Non-response & $5(7.2)$ & $4(6.7)$ & $1(11.1)$ & \\
\hline $\operatorname{CEVR}^{\mathrm{a}, \mathrm{e}}$ & & & & $>0.999^{\mathrm{b}}$ \\
\hline Yes & $65(95.6)$ & $56(94.9)$ & $9(100)$ & \\
\hline No & $3(4.4)$ & $3(5.1)$ & 0 & \\
\hline
\end{tabular}

Abbreviations: ALT, alanine transaminase; AST, aspartate transaminase; BC, buffy coat; cEVR, complete early virologic response; IQR, inter quartile range; $n$, number.

${ }^{\mathrm{a}}$ Values are expressed as No. (\%).

${ }^{\mathrm{b}}$ Fisher-exact test.

${ }^{\mathrm{c}}$ Values are expressed as median (IQR).

${ }^{\mathrm{d}}$ Mann-Whitney U test,

${ }^{\mathrm{e}}$ The data were missed in less than $10 \%$ of patients.

${ }^{\mathrm{f}}$ Chi-Square.

RNA in BCs, we compared the patients' baseline characteristics and on-treatment response (cEVR) between patients with residual HCV RNA in their BC samples and those with undetectable HCV RNA in their BC samples. In terms of the gender, age, HCV genotype, history of antiviral therapy, and levels of serum transaminases and HCV RNA, there was no difference between the 2 groups ( $\mathrm{P} \geq 0.05$; Table 1). Moreover, achievement of cEVR did not influence the rate of detection of HCVRNA in BC samples of patients with SVR to PegIFN and RBV treatment. However, the favorable genotypes of the 2 polymorphisms (rs12979860 CC and rs8099917 TT) near IFNL3 were more frequently observed in patients with undetectable HCV RNA in their BC samples than those with HCV RNA in their BC samples (rs12979860 CC, $45 \%$ vs. $22.2 \%, \mathrm{P}=0.016$ and $\mathrm{rs} 8099917 \mathrm{TT}, 66.7 \%$ vs. $33.3 \%$, $\mathrm{P}=0.01$ ) (Table 1). Moreover, patients with HCV RNA in their BC samples were more frequently harbored rs12979860 TT and rs8099917 GG genotypes than patients without HCV RNA in their BC samples (rs12979860 TT, 33.3\% vs. 5\%, P = 0.016 and rs8099917 GG, 11.1\% vs. 0\%, $\mathrm{P}=0.01$ ) (Table 1). 


\section{Discussion}

Replication of HCV in PBMC in spite of clearance of the virus from plasma has been described as occult HCV infection $(\mathrm{OCI})$ in recent years $(8,20)$. Despite the fact that hepatocytes are considered as the main target of HCV, experimental and clinical evidences strongly point to the presence of virus in cells of extrahepatic organs for invading and replication, particularly the immune system (21). In fact, extrahepatic reservoirs have important implications for transmission, disease progression, and effective treatment of HCV-infected patients. Clearance of HCV following antiviral treatment does not mean eradication of the virus from whole reservoirs (22). The presence of HCV RNA in PBMCs may lead to HCV reactivation in patients with SVR under special circumstances, such as immunosuppression (23).

In this study, although all patients had undetectable HCV RNA in their sera after achieving SVR with PegIFN and RBV, HCV RNA was still detected in isolated BCs of $13 \%$ of these patients. In contrast to our study, Inglot et al. (24) found $6.1 \%$ of patients with SVR to PegIFN and RBV had HCV RNA negative strand in their PBMC samples 24 weeks after termination of treatment. In another study, Fujiwara et al. (25) revealed that residual HCV RNA was not detected in plasma or PBMCs of any spontaneous or treatmentrecovered subjects suggesting that the classic pattern of recovery from $\mathrm{HCV}$ infection is generally equivalent to viral eradication. Gallegos-Orozco et al. (23) included 25 patients with SVR to PegIFN and RBV treatment 6 - 56 months (mean, 22 months) after the end of treatment and looked for HCV RNA in their PBMC samples following cell culture. They observed the persistence of viral RNA in the PBMCs of $5(20 \%)$ patients. Mohamad et al. (26) described that $26 \%$ of the SVR patients had a detectable level of HCV RNA in PBMC 6 month after completion of treatment. The current and all the mentioned studies, except the study done by Fujiwara et al. (25), found HCV RNA in the blood cells of the patients treated with IFN-based treatments. The difference in the reported rate of detection by these studies was mainly justified by the following points; different time points for detection of HCV RNA in PBMC after achieving SVR, various methods for detection of HCV RNA in the PBMC samples and different host and viral parameters of patients included. The question remaining is why the virus could be detected later in PBMC while cleared from the serum. One probable explanation is that HCV has developed a number of evasion mechanisms, infection of PBMCs being one of those where the virus can avoid the immune defense system, while hepatocytes remain the actual target. Previous works demonstrated that patients with seronegative HCV have an HCV-specific cellular immune response with a probable immune surveillance function, suggesting that host immune response is able to control but not to eliminate, $\mathrm{HCV}$ replication in these cases (27). It may also be that the virus developed some new quasi-species in PBMC that showed delayed response to the antiviral therapy but we could not confirm that speculation now.

The distribution of polymorphisms near IFNL3 in the current study was the same as the previous studies $(28,29)$ in Iranian patients with HCV infection. Based on our observations, polymorphisms near IFNL3 were associated with persistence of HCV RNA in BC samples of patients with SVR. The rs12979860 TT and rs8099917 GG, which classically are associated with treatment failure, were more frequently observed in patients with detectable HCV RNA in their BC samples. We hypothesized that polymorphisms near IFNL3 could play a very crucial role not only in spontaneous clearance of HCV and SVR rate after PegIFN and RBV therapy, but also in the clearance of HCV from BC after PegIFN and RBV therapy. In the study done by Angulo et al. (30), 79\% of hepatitis $C$ viremic patients had HCV RNA in their PBMC samples. In this study, patients with rs8099917 TG/GG were more frequently observed to have HCV RNA in their PBMC samples at the point of viremia. The mechanisms in which IFNL3 and host genetic variations causes such observation is not clear yet however discovery of IFNL4 gene near IFNL3 harboring rs12979860 and rs368234815 resulted in elucidation of different profiles of interferon stimulated genes expression, associated with treatment response to IFN-based regimens, by polymorphisms near or in IFNL3/IFNL4 genes (29, 31-33).

Unexpectedly we could not find any association of baseline viral load and other clinical parameters with final clearance of virus, while some researchers have shown an association of OCI with high cholesterol and triglyceride levels (34).

There were few limitations in this study including: 1 . The small sample size for the included patients with SVR, 2. We did not evaluate the HCV genotypes of the isolates from BC samples, and 3. The time span of blood sampling from the time point of achievement of SVR was not documented. The treatment of HCV has been revolutionized in the recent years and PegIFN and RBV will be not used as standard of care for treatment of patients with HCV infection. The new treatments are consisted of a combination of 2 or 3 direct-acting antiviral agents (DAAs), which can result in more than $90 \%$ SVR rate in patients with different condition of HCV infection (35). We believe that same study can be conducted in patients treated with DAAs. Moreover, it is crucial to evaluate the rate of HCV relapse in patients with SVR who has detectable HCV RNA in their PBMC samples especially under the circumstance of immunosuppression. In addition, it should be investigated if these patients have 
a higher chance of cirrhosis and HCC in long-term followup.

\subsection{Conclusions}

Hepatitis $C$ virus can be found in other reservoirs such as BC in a proportion of patients after successful treatment with PegIFN and RBV. Moreover, it seems IFNL3 polymorphisms can determine the persistence of HCV RNA in BC samples in patients after successful treatment course of PegIFN and RBV. The reactivation of HCV infection in patients harbor unfavorable IFNL3 genotypes following successful clearance of HCV viremia could be evaluated.

\section{References}

1. Hajarizadeh B, Grebely J, Dore GJ. Epidemiology and natural history of HCV infection. Nat Rev Gastroenterol Hepatol. 2013;10(9):553-62. doi: 10.1038/nrgastro.2013.107. [PubMed: 23817321].

2. Ghaderi-Zefrehi H, Gholami-Fesharaki M, Sharafi H, Sadeghi F, Alavian SM. The Distribution of Hepatitis C Virus Genotypes in Middle Eastern Countries: A Systematic Review and Meta-Analysis. Hepat Mon. 2016;16(9):ee40357. doi: 10.5812/hepatmon.40357. [PubMed: 27826320].

3. Hesamizadeh K, Alavian SM, Najafi Tireh Shabankareh A, Sharafi H. Molecular Tracing of Hepatitis C Virus Genotype 1 Isolates in Iran: A NS5B Phylogenetic Analysis with Systematic Review. Hepat Mon. 2016;16(12):ee42938. doi: 10.5812/hepatmon.42938. [PubMed: 28123445].

4. Jamalidoust M, Namayandeh M, Asaei S, Aliabadi N, Ziyaeyan M. Determining hepatitis $\mathrm{C}$ virus genotype distribution among high-risk groups in Iran using real-time PCR. World J Gastroenterol. 2014;20(19):5897-902. doi: 10.3748/wjg.v20.119.5897. [PubMed 24914351].

5. Veldt BJ, Saracco G, Boyer N, Camma C, Bellobuono A, Hopf U, et al. Long term clinical outcome of chronic hepatitis $\mathrm{C}$ patients with sustained virological response to interferon monotherapy. Gut. 2004;53(10):1504-8. doi: 10.1136/gut.2003.038257. [PubMed: 15361504].

6. Alavian SM, Hajarizadeh B, Bagheri Lankarani K, Sharafi H, Ebrahimi Daryani N, Merat S, et al. Recommendations for the Clinical Management of Hepatitis C in Iran: A Consensus-Based National Guideline. Hepat Mon. 2016;16(8):ee40959. doi: 10.5812/hepatmon.guideline. [PubMed: 27799966].

7. Blackard JT, Kemmer N, Sherman KE. Extrahepatic replication of HCV: insights into clinical manifestations and biological consequences. Hepatology. 2006;44(1):15-22. doi: 10.1002/hep.21283. [PubMed: 16799966].

8. Rezaee-Zavareh MS, Hadi R, Karimi-Sari H, Hossein Khosravi M, Ajudani R, Dolatimehr F, et al. Occult HCV Infection: The Current State of Knowledge. Iran Red Crescent Med J. 2015;17(11):ee34181. doi: 10.5812/ircmj.34181. [PubMed: 26734487].

9. Hubbard JJ, Kottilil S. Extra-hepatic replication of the hepatitis C virus: current issues and future directions. Future Virol. 2011;6(3):275-8. doi: $10.2217 /$ fvl.11.7.

10. Sharafi H, Alavian SM. IL28B polymorphism, Explanation for Different Responses to Therapy in Hepatitis C Patients. Hepat Mon. 2011;11(12):958-9. doi: 10.5812/kowsar.1735143X.794. [PubMed: 22368678].

11. Haj-Sheykholeslami A, Keshvari M, Sharafi H, Pouryasin A, Hemmati K, Mohammadzadehparjikolaei F. Interferon-lambda polymorphisms and response to pegylated interferon in Iranian hepatitis C patients. World J Gastroenterol. 2015;21(29):8935-42. doi: 10.3748/wjg.v21.i29.8935. [PubMed: 26269684].
12. Behnava B, Sharafi H, Keshvari M, Pouryasin A, Mehrnoush L, Salimi S, et al. The Role of Polymorphisms Near the IL28B Gene on Response to Peg-Interferon and Ribavirin in Thalassemic Patients With Hepatitis C. Hepat Mon. 2016;16(1):ee32703. doi: 10.5812/hepatmon.32703. [PubMed: 27110259].

13. Kadjbaf D, Keshvari M, Alavian SM, Pouryasin A, Behnava B, Salimi S, et al. The Prevalence of Hepatitis C Virus Core Amino Acid 70 Substitution and Genotypes of Polymorphisms Near the IFNL3 Gene in Iranian Patients With Chronic Hepatitis C. Hepat Mon. 2016;16(6):ee37011. doi: 10.5812/hepatmon.37011. [PubMed: 27630727].

14. Keshvari M, Alavian SM, Behnava B, Pouryasin A, Sharafi H. The interferon lambda 4 rs368234815 predicts treatment response to pegylated-interferon alpha and ribavirin in hemophilic patients with chronic hepatitis C. J Res Med Sci. 2016;21:72. doi: 10.4103/17351995.189678. [PubMed: 27904617].

15. Keshvari M, Alavian SM, Behnava B, Pouryasin A, Craig JC, Sharafi H. Impact of IFNL4 rs12979860 and rs8099917 polymorphisms on response to Peg-Interferon-alpha and Ribavirin in patients with congenital bleeding disorder and chronic hepatitis C.J Clin Lab Anal. 2016 doi: 10.1002/jcla.22063. [PubMed: 27735085].

16. Pouryasin M, Keshvari M, Sharafi H, Alavian SM, Behnava B, Alavian SE, et al. The ITPA and C20orfig4 Polymorphisms and Hematological Changes During Treatment With Pegylated-Interferon Plus Ribavirin in Patients With Chronic Hepatitis C. Hepat Mon. 2016;16(2):ee35278. doi: 10.5812/hepatmon.35278. [PubMed: 27148387].

17. Sharafi H, Alavian SM, Behnava B, Pouryasin A, Keshvari M. The Impact of IFNL4 rs12979860 Polymorphism on Spontaneous Clearance of Hepatitis C; A Case-Control Study. Hepat Mon. 2014;14(10):ee22649. doi: 10.5812/hepatmon.22649. [PubMed: 25419220].

18. Aalaei-Andabili SH, Behnava B, Salimi S, Sharafi H, Alavian SM. Mysterious Linkages Between Hepatitis C Virus Genotypes, Interleukin28B Genotypes and Viral Clearance- A Meta-Analysis. Hepat Mon. 2014;14(3):ee15895. doi: 10.5812/hepatmon.15895. [PubMed: 24734092].

19. Sharafi H, Pouryasin A, Alavian SM, Behnava B, Keshvari M, Mehrnoush L, et al. Development and Validation of a Simple, Rapid and Inexpensive PCR-RFLP Method for Genotyping of Common IL28B Polymorphisms: A Useful Pharmacogenetic Tool for Prediction of Hepatitis $C$ Treatment Response. Hepat Mon. 2012;12(3):190-5. doi: 10.5812/hepatmon.849. [PubMed: 22550527].

20. Rezaee-Zavareh MS, Ramezani-Binabaj M, Moayed Alavian S. Screening for occult hepatitis $C$ virus infection: Does it need special attention?. Hepatology. 2015;62(1):321-2. doi: 10.1002/hep.27626. [PubMed: 25476196].

21. Hanno AFF, Mohiedeen KM, Alshayeb AF, Deghedy A. HCV RNA in peripheral blood mononuclear cells (PBMCs) as a predictor of the response to antiviral therapy in chronic hepatitis C. Alexandria J Med. 2014;50(4):317-22. doi: 10.1016/j.ajme.2013.05.004.

22. Cavalheiro Nde P, Filgueiras TC, Melo CE, Morimitsu SR, de Araujo ES, Tengan FM, et al. Detection of HCV by PCR in serum and PBMC of patients with hepatitis $C$ after treatment. Braz Infect Dis. 2007;11(5):4714. [PubMed: 17962872].

23. Gallegos-Orozco JF, Rakela J, Rosati MJ, Vargas HE, Balan V. Persistence of hepatitis $C$ virus in peripheral blood mononuclear cells of sustained viral responders to pegylated interferon and ribavirin therapy. Dig Dis Sci. 2008;53(9):2564-8. doi: 10.1007/s10620-008-0323-x. [PubMed: 18594984].

24. Inglot M, Pawlowski T, Szymczak A, Malyszczak K, Zalewska M, Radkowski M. Replication of hepatitis C virus in peripheral blood mononuclear cells in patients with chronic hepatitis $\mathrm{C}$ treated with pegylated interferon alpha and ribavirin. Postepy Hig Med Dosw (Online). 2013;67:186-91. [PubMed: 23619217].

25. Fujiwara K, Allison RD, Wang RY, Bare P, Matsuura K, Schechterly C, et al. Investigation of residual hepatitis $\mathrm{C}$ virus in presumed recovered subjects. Hepatology. 2013;57(2):483-91. doi: 10.1002/hep.25921. [PubMed: 22729600]. 
26. Mohamad HI, El-Bab HK, Kamal AM. HCV RNA in serum and peripheral blood mononuclear cells after successful interferon therapy. Hepatogastroenterology. 2011;58(107-108):932-6. [PubMed: 21830419].

27. Bartolome J, Castillo I, Quiroga JA, Carreno V. Interleukin-28B polymorphisms and interferon gamma inducible protein-10 serum levels in seronegative occult hepatitis C virus infection. J Med Virol. 2016;88(2):268-74. doi: 10.1002/jmv.24322. [PubMed: 26147900].

28. Sharafi H, Pouryasin A, Alavian SM, Behnava B, Keshvari M, Salimi S, et al. Distribution of IL28B Genotypes in Iranian Patients with Chronic Hepatitis C and Healthy Individuals. Hepat Mon. 2012;12(12):ee8387. doi: 10.5812/hepatmon.8387. [PubMed: 23550102].

29. Keshvari M, Pouryasin A, Behnava B, Sharafi H, Hajarizadeh B, Alavian SM. Letter: the rs12979860 and ss469415590 polymorphisms of IFNL4 gene are in strong linkage disequilibrium in Caucasian patients with chronic hepatitis C. Aliment Pharmacol Ther. 2014;39(3):343. doi: 10.1111/apt.12589. [PubMed: 24397325].

30. Angulo J, Pino K, Pavez C, Biel F, Labbe P, Miquel JF, et al. Genetic variations in host IL28B links to the detection of peripheral blood mononuclear cells-associated hepatitis C virus RNA in chronically infected patients. J Viral Hepat. 2013;20(4):263-72. doi: 10.1111/jvh.12076. [PubMed: 23490371].
31. Pouryasin M, Sharafi H, Behnava B, Alavian SM, Keshvari M, Pouryasin A. A Simple PCR-RFLP Method for Genotyping of IFNL4 rs368234815 Polymorphism in Patients With Chronic Hepatitis C. Lab Med 2017;48(1):51-6. doi: 10.1093/labmed/lmw060. [PubMed: 28057801].

32. Prokunina-Olsson L, Muchmore B, Tang W, Pfeiffer RM, Park H, Dickensheets $\mathrm{H}$, et al. A variant upstream of IFNL3 (IL28B) creating a new interferon gene IFNL4 is associated with impaired clearance of hepatitis C virus. Nat Genet. 2013;45(2):164-71. doi:10.1038/ng.2521. [PubMed 23291588].

33. Keshvari M, Sharafi H. Interferon-lambda Genetic Variations and Hepatitis C: Yet to be Discovered. Hepat Mon. 2014;14(5):ee19433. doi 10.5812/hepatmon.19433. [PubMed: 24976835].

34. Muazzam AG, Qureshi S, Mansoor A, Ali L, Iqbal M, Siddiqi S, et al Occult HCV or delayed viral clearance from lymphocytes of Chronic HCV genotype 3 patients after interferon therapy. Genet Vaccines Ther. 2011;9(1):14. doi: 10.1186/1479-0556-9-14. [PubMed: 21892969].

35. Hesamizadeh K, Sharafi H, Rezaee-Zavareh MS, Behnava B, Alavian SM. Next Steps Toward Eradication of Hepatitis C in the Era of Direct Acting Antivirals. Hepat Mon. 2016;16(4):ee37089. doi: 10.5812/hepatmon.37089. [PubMed: 27275164]. 